\title{
Erratum zu: Max Wertheimer
}

\section{Erratum zu: \\ V. Sarris, Max Wertheimer, Klassische Texte der Wissenschaft, https://doi.org/10.1007/978-3-662-59821-4}

Eine fehlende Seite des Originaltextes wurde nach S. 37 eingefügt. Die Seitenzählung der folgenden Seiten erhöht sich um jeweils 1.

Das Komma im Buchtitel wurde entfernt und „Produktives Denken“ ist nun der Untertitel.

Die korrigierten Versionen sind verfügbar unter https://doi.org/10.1007/978-3-662-59821-4_2

https://doi.org/10.1007/978-3-662-59821-4 